\title{
Genetics and Expression Analysis of Anthocyanin Accumulation in Curd Portion of Sicilian Purple to Facilitate Biofortification of Indian Cauliflower
}

\author{
Shrawan Singh ${ }^{1 *}$, Pritam Kalia ${ }^{1}$, Rahul Kumar Meena ${ }^{1}$, Manisha Mangal ${ }^{1 *}$, Sabina Islam ${ }^{1}$, \\ Supradip Saha ${ }^{2}$ and Bhoopal S. Tomar ${ }^{1}$ \\ ${ }^{1}$ Division of Vegetable Science, ICAR-Indian Agricultural Research Institute, New Delhi, India, ${ }^{2}$ Division of Agricultural \\ Chemicals, ICAR-Indian Agricultural Research Institute, New Delhi, India
}

OPEN ACCESS

Edited by:

Ryo Fujimoto,

Kobe University, Japan

Reviewed by:

Zhao Zhenqing,

ZheJiang Academy of Agricultural Sciences, China

Hamid Khazaei,

University of Saskatchewan, Canada

*Correspondence:

Shrawan Singh

shrawansingh@iari.res.in

Manisha Mangal

manishamangal@rediffmail.com

Specialty section:

This article was submitted to

Plant Breeding,

a section of the journal

Frontiers in Plant Science

Received: 26 July 2019 Accepted: 17 December 2019

Published: 30 January 2020

Citation:

Singh S, Kalia P, Meena RK, Mangal M, Islam S, Saha S and

Tomar BS (2020) Genetics and Expression Analysis of Anthocyanin

Accumulation in Curd Portion of

Sicilian Purple to Facilitate Biofortification of Indian Cauliflower.

Front. Plant Sci. 10:1766.

doi: 10.3389/fpls.2019.01766
The present study was undertaken to know the genetics of purple color of cauliflower curds using a Sicilian purple 'PC-1' and a white curding mid-late group genotype of Indian cauliflower. For this, a cross was attempted between 'DC-466' (white curd) and 'PC-1' (purple curd) and observed intermediate level of purple pigmentation on curds in $F_{1}$ plants. Segregation of $F_{2}$ population (173) revealed that the purple color of the curd was governed by a single gene dominant over white, but the expression of trait was incomplete. It was substantiated by segregation of plants of $\mathrm{BC}_{1}$ and $\mathrm{F}_{2: 3 \text { (intermediate) }}$ generations into 1 (white):1(intermediate) and 1(white):2(intermediate):1(intense), respectively. The $F_{2}, B_{1}$, and $B_{2}$ generations segregated into purple(intermediate to intense): white curding plants in the ratio of 126: $47,26: 24$, and 40:0, respectively fitting well with the Mendelian ratio of single gene for purple curds. However, purple pigmentation on curds ranged from very light to intense, which corroborated with the wide range of anthocyanin content in $\mathrm{F}_{2}$ (3.81-48.21 mg/100 g fw). Out of three molecular markers from high resolution map of $\mathrm{Pr}$ gene in purple color cauliflower 'Graffiti', only BoMYB3 marker could distinguish purple and white curding parents but did not show co-segregation while investigated in $F_{2}$ population. Expression of BOMYB1 gene was up regulated in both the purple curd genotypes 'PC-1' and 'Graffiti' in comparison to white curded 'DC-466', while BoMYB2 gene was slightly upregulated in 'PC-1' but down regulated in 'Graffiti'. Occurrence of 'broccoli type' $F_{2}$ individuals and their genetic stability in $F_{2: 3}$ support the intermediate position of 'Sicilian purple' between broccoli (Calabrese) and cauliflower. There was not any correlation between curd coloration and pigmentation on apical leaf and stem portion, indicating difference of expression in 'PC-1' than 'Graffiti'. The information obtained is useful for breeding anthocyanin rich attractive purple curding 'specialty cauliflower' for better consumer health and growers' earnings.

Keywords: Brassica oleracea var. botrytis, Brassica oleracea var. italica, pigmentation, high performance liquid chromatography, RT-PCR, molecular markers 


\section{INTRODUCTION}

Novel plants always attracted humans for health and nutrition purposes, and their acceptance remains high in case the regulating gene(s) are natural mutants. Purple color in plants is due to anthocyanins which have strong free radical scavenging activity and, thereby, good for health (Hwang et al., 2012). They belong to flavonoid group of polyphenol and impart red, purple, blue colors, and their different shades to plant parts to attract pollinators and consumers. They have biological functions in plants and human health due to metal chelation, positively charged oxanium, hydrogen donation, and protein binding properties (Kong et al., 2003). In plants, they protect chloroplast from photo-oxidative and photo-inhibitory damages caused by free radicals and ultra violet B light (Klaper et al., 1996) and for modification of captured light quality and quantity (Barker et al., 1996; Dodd et al., 1998). In human beings, anthocyanins help in reinforcing the critical balance between production and neutralizing reactive oxygen species (ROS) and reactive nitrogen species (RNS), thereby reducing the oxidative stress (Ozcan and Ogun, 2015). Preventive role of anthocyanins also reported against atherosclerosis, venous insufficiency, cardiovascular diseases, certain cancers, and other chronic diseases (Lila, 2004). In vitro studies further revealed inhibitory role of anthocyanins for activities of COX-1 and COX-2 genes which are involved in tumorigenesis (Hou et al., 2004a; Christian et al., 2006; Welch et al., 2008), induction of apoptosis of human promyelocytic leukemia (HL-60) cells due to specific ortho position of the hydroxyls in some anthocyanidins (Hou et al., 2003) and inhibition of activator protein 1 (AP-1) transcriptional activity and cell transformation (Hou et al., 2004b). Although, there is no specific recommended dietary guidelines for anthocyanins but the Chinese Nutrition Society (2013) proposed $50 \mathrm{mg} /$ capita/day while FAO/WHO Expert Committee extended the specific proposed level to $2.5 \mathrm{mg} / \mathrm{kg}$ human body weight/day (for grape skin) (Wallace and Giusti, 2015). On the other side, the toxicity level of anthocyanins is also not observed in rats even up to $20 \mathrm{mg} /$ $\mathrm{kg}$ body weight of rats and $25 \mathrm{mg} / \mathrm{kg}$ body weight of mice. Therefore, taking anthocyanin rich foods appears to be good for consumers' satisfaction and health attributed by their intrinsic biological functions. More than 600 types of anthocyanins have been reported in plants but only six of them such as pelargonidin, cyanidin, peonidin, delphinidin, petunidin, and malvidin contribute $90 \%$ of anthocyanin present in the nature and 50\% of them are acylated (added with acyl group, $\mathrm{R}-\mathrm{C}=\mathrm{O}$ ).

Among the members of Brassica oleracea L., anthocyanin biosynthesis and accumulation occurs due to natural mutations as reported for purple cauliflower by Chiu et al. (2010).It has been genetically investigated for curd (pre-floral apical meristem) in purple cauliflower variety 'Graffiti' as a single semi-dominant gene $\operatorname{Pr}$ (Chiu et al., 2010), in ornamental kale as a single dominant gene $\mathrm{BoPr}$ for purple leaf (Liu et al., 2017), BrPur gene in Chinese cabbage (Wang et al., 2014), and similarly red leaf trait by a single dominant $R e$ gene in ornamental kale (Ren et al., 2015). Genetic regulation of red leaf color in cabbage was indicated by Yuan et al. (2009) but nature of genetics has not been proposed yet. In cauliflower, the variety 'Graffiti' represents late or European group of cauliflower and obligatorily requires $10-16^{\circ} \mathrm{C}$ for curd initiation and development and $4-7^{\circ} \mathrm{C}$ for $5-6$ weeks for vernalization. It produces typical 'curd', which is a modified pre-floral apical meristem. We could observe that it produces good quality curds during January end to February months in plains of North India, but bolting (elongation of flower stalk) and seed setting does not occur due to deficit of vernalization period. Alternatively, 'Sicilian purple' is botanically an intermediate of broccoli and cauliflower (Gray, 1982; Branca et al., 2018) and appears closer to broccoli. It forms curd-like heads at a temperature range of 16 to $25^{\circ} \mathrm{C}$ and does not require vernalization but needs cold temperature for bolting and flowering. Hence, it produces attractive full size cauliflower-like curds during December-March months, set seeds profusely, and is easily crossable with Indian cauliflower (Singh et al., 2019). Unlike 'Graffiti', it accumulates anthocyanin only in 'pre-floral rudimentary buds' (Figure 1) demonstrating the difference in genetic regulation of anthocyanin content between the two varieties. Although, Quiros and Farnham (2011) did mention the view of $\mathrm{N}$. Acciarri that purple curd in 'Sicilian purple' governed by a recessive gene but we could observe intermediate type in $F_{1}$ cross which contradicts the previous statement. Hence, it was required to investigate the genetics of purple curd in 'Sicilian purple' to plan its introgression in commercial varieties of broccoli and different maturity groups in cauliflower. Because, cauliflower and broccoli are important vegetable crops which are being grown worldwide on 1395152 ha with a production of 25984758 tons annually (FAOSTAT, 2017). It is $5^{\text {th }}$ important vegetable crop in India (which stand $2^{\text {nd }}$ after China) cultivated on 454,000 ha area with $8,557,000$ tons production (NHB Database, 2017). It has large consumer base across the geographic regions and economic strata of Indian population and biofortifying this crop with health beneficial compounds like anthocyanins can benefit public sustainably.

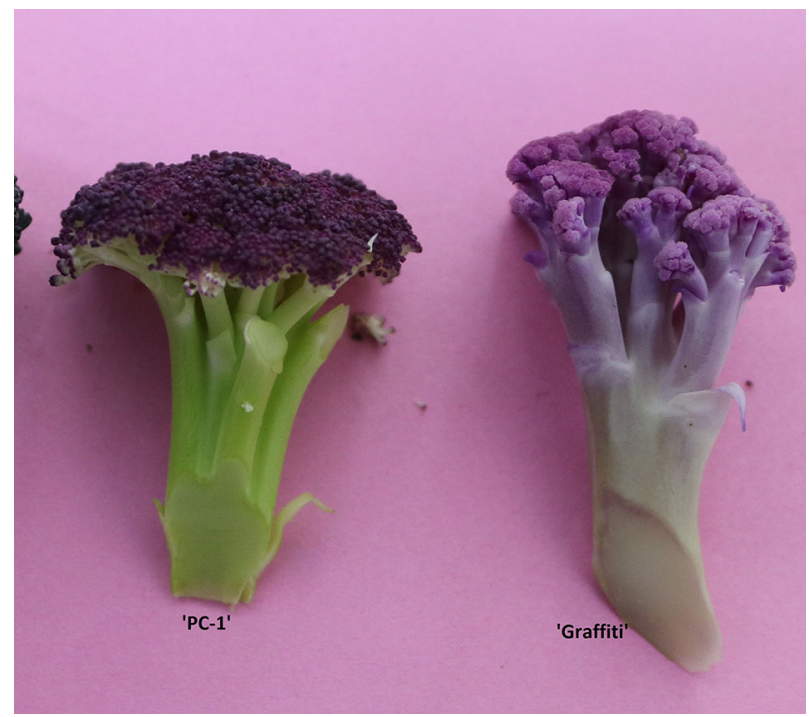

FIGURE 1 | Anthocyanin pigmentation in curd fractions of 'PC-1' and 'Graffiti'. 
Anthocyanin biosynthesis is a conserved pathway in plants and transcriptional regulation of three structural genes, namely R2R3MYB transcription factors, basic helix loop-helix (bHLH), and WD40 proteins appears to be the major mechanism to control this pathway (Broun, 2005). In Arabidopsis, accumulation of anthocyanins in vegetative tissues is mediated by four MYB proteins, namely PAP1 (Production of Anthocyanin Pigment1), PAP2, MYB113, and MYB114 and three bHLH proteins (Transparent Test8, Glabra3, and Enhancer of Glabra3) (Nesi et al., 2000; Gonzalez et al., 2008). As MYB transcription factor play an important role in accumulation of anthocyanins by regulating the transcription of structural genes. The $\operatorname{Pr}$ gene is a natural mutant in cauliflower itself and encodes for R2R3MYB transcription factor that exhibits tissue specific expression (Chiu et al., 2010). They indicated that Harbinger DNA transposon insertion in the upstream regulatory region of $\operatorname{Pr}$-D gene governs the changes in anthocyanin accumulation in cauliflower 'Graffiti'. But there is variation for (i) sink parts such as flowers, leaves, fruits, and stem among the botanical species and/or varieties, (ii) kind of predominant anthocyanins, and (iii) content value across the species and genotypes emphasize for case by case genetic studies. In some crops, such as Arabidopsis, the MYB factors require a bHLH in regulating anthocyanin biosynthesis (Gonzalez et al., 2008) while in crops like maize, each of them can act alone to activate transcription (Grotewold et al., 2000).

Identification of molecular markers is essential to handle the breeding materials for this environmental sensitive semidominant trait during introgression process (Yuan et al., 2009). They designed 17 gene-specific primers using highly homologous sequences in B. oleracea genome with Arabidopsis anthocyanin genomic information, all of them distinguished purple and green types. These markers were used by Chiu et al. (2010), and they isolated the $\operatorname{Pr}$ gene from cultivar 'Graffiti' through candidate gene-fine mapping analysis and developed a high resolution genetic map with three PCR-based markers, namely BoMYB2, BoMYB3, and BoMYB4 $(<0.2 \mathrm{cM})$ linked to $\operatorname{Pr}$ gene. The cauliflower (B. oleracea var. botrytis), cabbage ( $B$. oleracea var. capitata), broccoli ( $B$. oleracea var. italica), and kale (B. oleracea var. acephala) are different botanical varieties of $B$. oleracea, hence chances of crosstransferability of markers is expected to be high. But, due to difference in evolutionary levels, validation of markers in Sicilian purple type was essential to use them in marker assisted introgression scheme.

Nutritionally enriched varieties with different nutrients and colors have promise, both for farmers to get premium price and for consumers as health food (Birol et al., 2015). The exotic 'purple cauliflower' material, although, remains suitable to grow for availability for only a short period, presently from December to January months, but it can be extended to mid-March (Singh et al., 2019). However, there is a huge demand for cauliflower both from growers' and consumers' for the entire rest of the year (Kalia et al., 2016) highlighting the need to develop genotypes for other maturity groups. With this background, the study was undertaken to (i) investigate genetics of purple color curds and anthocyanin content in Sicilian purple derived line 'PC-1' using Indian cauliflower as background and, (ii) validate the available linked markers from high resolution map of $\operatorname{Pr}$ gene in 'Graffiti' variety of purple cauliflower by molecular and gene expression studies.

\section{MATERIALS AND METHODS}

\section{Breeding Materials and Growing Conditions}

In present study, we used a purple cauliflower genotype 'PC-1' derived by recurrent breeding from 'Sicilian purple' at the Division of Vegetable Science, ICAR- IARI, New Delhi. Unlike 'Graffiti', it accumulated anthocyanin only in pre-floral buds (which constitute curds or heads) and not in stalk which retain attractive light green color holding, thereby, a unique purplelight green color combination to attract consumers' preference. The breeding material for the study was generated by a breeding procedure depicted in Figure 2. In this, the 'PC-1' was crossed with 'DC-466', a white curding genotype of mid-late group of Indian cauliflower. $\mathrm{F}_{1}$ plants (28) from this were raised and two plants selfed by bud-pollination (2-3 days prior to anthesis) to generate $\mathrm{F}_{2}$ and were simultaneously backcrossed with parent genotypes 'DC-466' and 'PC-1' to develop $\mathrm{B}_{1}$ and $\mathrm{B}_{2}$ generations, respectively (Figure 2). The research farm is located in ICARIARI, New Delhi which has $28.63 \mathrm{~N}$ altitude and $77.15 \mathrm{E}$ longitude with mean sea level being 228.61 meters. Mean monthly temperature during crop growing months i.e. October, November, December, and January were $26.3^{\circ} \mathrm{C}, 20.8^{\circ}$ C, $15.7^{\circ} \mathrm{C}, 14.3^{\circ} \mathrm{C}$, and $16.8^{\circ} \mathrm{C}$, respectively.

All the populations $\mathrm{F}_{2}, \mathrm{~B}_{1}, \mathrm{~B}_{2}$, and $\mathrm{F}_{1}$ along with parents were sown in nursery beds $(3.0 \times 0.45 \times 0.20 \mathrm{~m})$ during September 2017 and 30 days old seedlings were transplanted on raised beds $(\approx 15 \mathrm{~cm})$ during October, 2017 at a spacing of $60 \times 45 \mathrm{~cm}$ and the standard crop growing practices were followed as described by Singh and Sharma (2003). Well decomposed farm yard manure (FYM), nitrogen, phosphorus, and potash @ 25 t, 100 $\mathrm{kg}, 60 \mathrm{~kg}$, and $50 \mathrm{~kg}$ per hectare, respectively were applied to the crop. Adequate soil moisture was maintained by regular irrigation at 7-10 days interval for proper crop growth and to avoid moisture stress which otherwise influence intensity of pigmentation.

Curd traits were observed from each individual of $F_{2}, B_{1}, B_{2}$, and $F_{1}$ and parents using standard rulers and digital weighing balance. Curd color was observed through visual observation for presence or absence of purple pigmentation. Chiu et al. (2010) classified $\mathrm{F}_{2}$ plants into three categories i.e. white, light purple, and purple curds. We could, however, see a range of curd pigmentation in the segregating material. Hence, a phenotyping scale for purple curd trait was devised with ' $0-5$ ' score wherein, ' 0 ' - white, ' 1 ' - white base with slight purple dotlike pigmentation in parts of curd, ' 2 ' - whitish curds with light purple pigmentation on entire curd, ' 3 '-light purple curds devoid of white color appearance, ' 4 '-medium purple, and 
'Sicilian Purple Cauliflower'

(Segregation exotic material)

- Selfing of selected 10-12 plants for 3 generations

- Selection for plant stature, curd traits

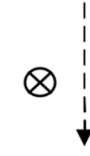

'DC-466' (fixed inbred) $\times$ 'PC-1' (Stabilized genotype)

(ㅇ)

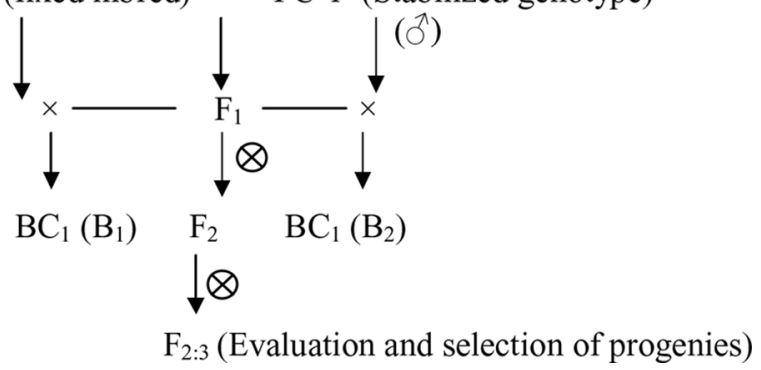

FIGURE 2 | Population development procedure used in the study.

'5'-intense purple (Figure 3). Royal Horticultural Society color chart of Purple Group was used for clarification. The plants were also scored for purple pigmentation on stem and apical portion and curds were categorized based on texture. Further, $103 \mathrm{~F}_{2}$ individuals including 94 purple (88 intermediate and six intense) and nine white curding were advanced to $\mathrm{F}_{2: 3}$ generation which were evaluated for curd traits during September 2018 to January 2019 period. Crop growing conditions and evaluation process of $\mathrm{F}_{2: 3}$ progenies were same as that of earlier generations.

\section{Anthocyanin Determination}

The sampling for anthocyanin determination in curd portion was carried out between 9.30-10.30 AM from the marketable curds (20-21 days after curd initiation) by cutting 2-3 well grown knobs (independent segments of curd, 15-20 g) with sharp knife and brought to lab in ice-box. The sampling at 20-21 days after curd initiation was based on a pre-sampling investigation performed from 3 to 24 days after curd initiation in 'PC-1'. Curd samples were taken from 8 to 10 plants in each of $103 \mathrm{~F}_{2: 3}$ progenies and bulked to represent respective progeny for analysis.

Total anthocyanins content were determined by $\mathrm{pH}$ differential method (Fulecki and Francis, 1968) as described by Chiu et al. (2005) and Yuan et al. (2009) with minor modification. In brief, $1 \mathrm{~g}$ sample was grounded in pestlemortar separately with $20 \mathrm{~mL}$ of $\mathrm{pH} 1.0$ buffer $(1.86 \mathrm{~g} \mathrm{KCl}$ in $980 \mathrm{~mL}$ water, added ca. $6.3 \mathrm{~mL} \mathrm{HCl}$, made volume to $1 \mathrm{~L}$ with water) and $20 \mathrm{~mL}$ of $\mathrm{pH} 4.5$ buffer $\left(54.43 \mathrm{~g} \mathrm{CH}_{3} \mathrm{CO}_{2} \mathrm{Na} \cdot 3 \mathrm{H}_{2} \mathrm{O}\right.$ in $960 \mathrm{~mL}$ water, add ca $20 \mathrm{~mL} \mathrm{HCl}$, make volume to $1 \mathrm{~L}$ with water). Mixture was centrifuged at $12,000 \mathrm{~g}$ for $15 \mathrm{~min}$ at $4^{\circ} \mathrm{C}$ in refrigerated centrifuge (Sigma-Aldrich). Supernatant was filtered through Whatman No. 1 filter paper and diluted to a standard volume $(25 \mathrm{~mL})$. Absorbance was recorded at $520 \mathrm{~nm}$ using spectrophotometer (Eppendorf, Hamburg, Germany). Samples were analyzed in duplicate and mean values were taken for analysis. Total anthocyanin content (TAC) in samples were expressed as cyaniding-3-glucoside (C3G) equivalent and calculated using the following equation: TAC $(\mathrm{mg} / 100 \mathrm{~g} \mathrm{fw})=$ $\left(\mathrm{Abs}_{510}\right.$ at $\mathrm{pH} 1.0-\mathrm{Abs}_{510}$ at $\left.\mathrm{pH} 4.5\right) \times 449.2 / 26,900 \times$ dilution factor. Here, 449.2 is molecular weight of cyaniding-3-glucoside and 26,900 is molar extinction coefficient.

\section{HPLC Analysis of Anthocyanin}

Identification of prominent anthocyanin in curd portion of purple cauliflower 'PC-1' and 'Graffiti' as reference sample was done by reverse phase-high performance liquid chromatography (RP-HPLC) as per the procedure described by Yuan et al. (2009). For this analysis, $0.5 \mathrm{mg}$ sample was extracted thrice in $25 \mathrm{~mL}$ of methanol: water: acetic acid (85:15:05) by grinding to colorless state using pestle and mortar at room temperature under dark condition. The extract was centrifuged at $12,000 \mathrm{~g}$ for $10 \mathrm{~min}$ at $4^{\circ}$ $\mathrm{C}$ in refrigerated centrifuge. Supernatant was collected and filtered through Whatman No. 1 filter paper and concentrated to $1 \mathrm{~mL}$ volume by rotary evaporator. The extract was diluted with water and samples were analyzed using HPLC with a diode array detector (Waters, Milford, MA). Twenty microliters of the sample was injected into SB-C18 $(4.6 \times 250 \mathrm{~mm}, 5 \mu \mathrm{m})$ column (Agilent Technologies, Rising Sun, MD, USA) and eluted using a mobile phase consisting of solvent A (5\% formic acid: $95 \%$ water) and solvent B (100\% methanol) at a flow rate of $1.0 \mathrm{~mL} / \mathrm{min}$ and detection was done at $520 \mathrm{~nm}$ for $40 \mathrm{~min}$ run time. The elution program was followed as described by Wu and Prior (2005). The major individual anthocyanin peak were putatively identified based on previous publications with mass spectrometric analysis (Wu and Prior, 2005; Yuan et al., 2009; Chiu et al., 2010).

\section{Molecular Markers and PCR Analysis}

Genomic DNA from young leaf samples of parents, $F_{1}$ and $F_{2}$ plants was isolated using CTAB method of Saghai-Maroof et al. (1984). Quality and quantity of DNA from each sample was estimated using ethidium bromide staining on $0.8 \%$ agarose gels. From $F_{2}$, two bulks were made by using 10 individuals of each 


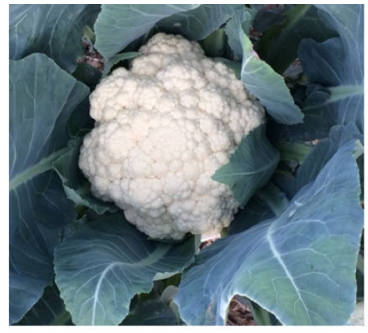

'DC-466'

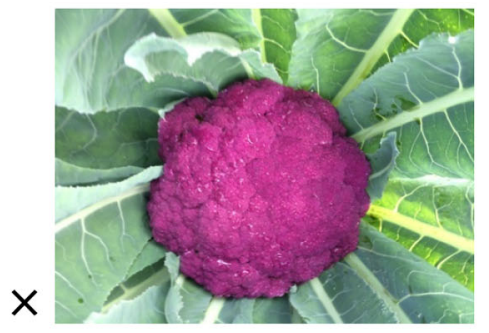

'PC-1'

$\mathrm{F}_{1}$
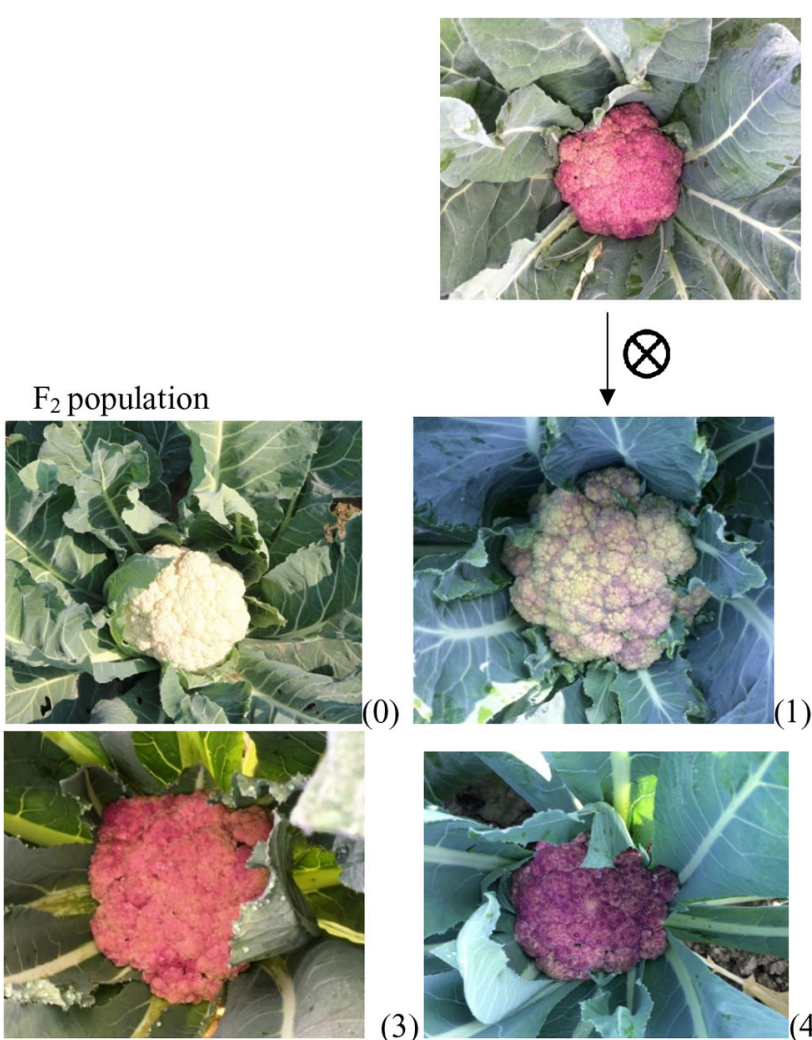

(0)
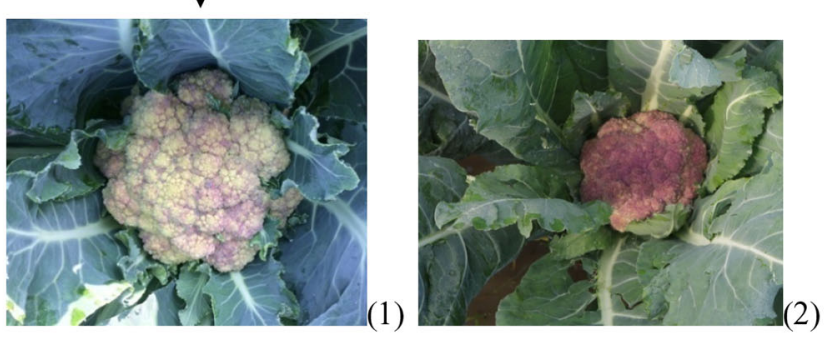

(3)

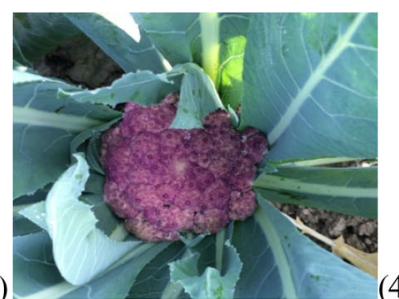

(4)
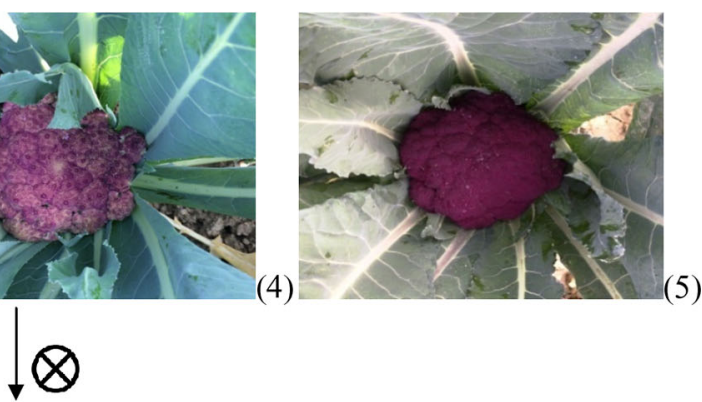

$\mathrm{F}_{2: 3}$ population

FIGURE 3 | Observed curd color phenotypes of parents, $F_{1}$, and $F_{2}$ population. Curd color scale of ' $0-5$ '; $0=$ white, $1-4=$ light to intermediate purple;

$5=$ intense purple.

white and intense purple curding group. Genomic DNA was also extracted from five white curding genotypes, namely Pusa Shukti (401), DC-402, Pusa Himjyoti (PHJ), Pusa Sharad (309), and Pusa Paushja (476) and two of broccoli genotypes (PS-Palam Samridhi and PB-Pusa purple broccoli) for initial screening of markers.

A total of nine molecular markers from Chiu et al. (2010) were got synthesized from Sigma Chemicals Co. USA (Supplementary Table 1). Of them, three PCR based markers, namely BoMYB2, BoMYB3, and BoMYB4 were depicted on high-resolution genetic resolution map of $\operatorname{Pr}$ gene which spanned within $0.2 \mathrm{cM}$. The PCR reaction volume was $10 \mu \mathrm{l}$ consisting of $50 \mathrm{ng}$ genomic DNA, $5 \mu \mathrm{l}$ of $2 \mathrm{X}$ master mix (OnePCRTM, GeneDireX) and $1.0 \mu \mathrm{M}$ of each primer $(0.5 \mu \mathrm{l}$ forward and reverse equally). The PCR conditions were $94^{\circ} \mathrm{C}$ for $0.5 \mathrm{~min} ; 35$ cycles of $94^{\circ} \mathrm{C}$ for $30 \mathrm{~s}, 56-60^{\circ} \mathrm{C}$ for $30 \mathrm{~s}$, and $72^{\circ} \mathrm{C}$ for $1 \mathrm{~min}$; and a final extension at $72^{\circ} \mathrm{C}$ for $10 \mathrm{~min}$ (Chiu et al., 2010). The PCR-amplified DNA products were resolved by 
submerged horizontal electrophoresis (BioRad, USA) at a constant voltage of $120 \mathrm{~V}$ for $3 \mathrm{~h}$ using $4 \%(\mathrm{w} / \mathrm{v})$ agarose gel and visualized under UV light fluorescence using Gel documentation system (Alpha imager, Cell Biosciences, Santa Clara, CA). The PCR products from marker analysis were scored visually for presence or absence of bands and their sizes were determined by use of 50 bp reference marker.

\section{RNA Extraction and Expression Analysis of BoMYB Genes Using Q-PCR Analysis}

Four $M Y B$ genes, namely BoMYB1, BoMYB2, BoMYB3, and $B o M Y B 4$ were studied for their expression pattern in parents, DC-466(P1), 'PC-1' $\left(\mathrm{P}_{2}\right)$, and 'Graffiti' (as reference). Already published primer sequences of these genes (Chiu et al., 2010) were used for the study. For this, curd samples were collected in morning hours in liquid $\mathrm{N}_{2}$ and stored in deep freezer $\left(-80^{\circ} \mathrm{C}\right)$ until RNA isolation. Three biological replicates were collected from each line. Total RNA from each sample was extracted using Tri-Xtract (G Biosciences, Geno Technology, Inc. St. Louis USA) following manufacturer's guidelines and quantified with a nano spectrophotometer. $1 \mu \mathrm{l}$ of isolated RNA was loaded on a denaturing agarose gel to check its concentration and integrity. $2 \mu \mathrm{g}$ of total RNA was reverse transcribed using Verso cDNA synthesis kit (Thermo Fisher Scientific, Inc.) following manufacturer's instructions. Tenfold dilution of cDNA was made and $1 \mu \mathrm{l}$ of diluted cDNA was used as a template for each qPCR reaction. For a $10 \mu \mathrm{l}$ qRT-PCR reaction, $5 \mu \mathrm{l}$ of 2XSYBR Green master mix (Applied Biosystem, CA,USA), $2 \mu \mathrm{l}$ nuclease free water, $1 \mu \mathrm{l}$ each of forward and reverse primer of desired gene $(100 \mathrm{~nm})$ and $1 \mu \mathrm{l}$ of template DNA was used. qRTPCR analysis was performed on LightCycler ${ }^{\circledR} 96$ Real-Time PCR (Roche Diagnostics Corporation, Indianapolis, USA). The QPCR program comprised of initial denaturation at $95^{\circ} \mathrm{C}$ for $120 \mathrm{~s}$, 40 cycles of denaturation at $95^{\circ} \mathrm{C}$ for $30 \mathrm{~s}$, annealing at $55^{\circ} \mathrm{C}$ for $60 \mathrm{~s}$, and extension at $72^{\circ} \mathrm{C}$ for $30 \mathrm{~s}$. For Q-PCR two technical replicates were used per biological replicate of each genotype. The $\Delta \mathrm{Ct}$ value of each target gene was normalized with internal control Bo18S. The $\Delta \Delta \mathrm{Ct}$ values were calculated taking $\Delta \mathrm{Ct}$ value of 'DC-466' as calibrator and were used to plot graph to study the relative expression of each gene in the genotypes.

\section{Statistical Analysis}

Mean, range, and standard deviation for data from anthocyanin content in plant materials was analyzed by use of Microsoft Excel software. The genetic analyses of curd color, apical, and stem pigmentation and curd texture in $\mathrm{F}_{2}$ and $\mathrm{F}_{2: 3}$ were done by chisquare test using MS Software. Correlation analysis between curd color, apical, and stem pigmentation was performed by online OPSTAT software.

\section{RESULTS}

\section{Anthocyanin Rich 'PC-1' Inbred Line}

Recurrent selection was performed using an exotic purple cauliflower 'Sicilian purple' which resulted into a promising 'purple cauliflower-1' (or 'PC-1') genotype. It has erect bluish green leaves, purple pigmentation on apical shoot and forms intense purple circular curds of 850-940 g weight. Its maturity period coincides with mid-late group of Indian cauliflower, i.e. from December end to mid-January which can extend up to midMarch by shifting planting dates.

\section{Pr Gene Governs Purple Curds in Cauliflower}

All the 28 plants from 'DC- $466^{\prime} \times$ 'PC-1' $\mathrm{F}_{1}$ cross produced an intermediate color curd phenotype, mostly of cauliflower-like curd shape with light purple pigmentation (Figure 3) indicating incomplete dominance of purple curds. The $\mathrm{F}_{2}$ population (173 plants) showed the monogenic segregation ratio of $1: 3\left(\chi^{2}=0.93\right.$, $\left.\mathrm{P}_{1 \mathrm{df}}=3.48\right)$ with 47 white: 126 purple (including intermediate) plants. In $\mathrm{F}_{2}$, the intermediate phenotype had a range from light to medium purple, however, they were distinct from typical white curd trait of 'DC-466', hence they were merged into purple category. Further, the 173 individual $\mathrm{F}_{2}$ plants segregated into six minor groups viz., white, white base with slight purple dot-like pigmentation in parts of curd, whitish curds with light purple pigmentation on entire curd, light purple curds devoid of white color appearance, medium purple, and intense purple depicted as ' $0-5$ ' score in Figure 3. The grouping of $F_{2}$ plants resulted into three prominent classes of curd color such as white (47): purple (Light-medium) $(95)$ : purple $_{(\text {Intense) }}$ (31), which segregated into 1:2:1 ratio (Table 1) substantiating the single locus governance of purple color of curd in source genotype. These results suggests that the purple color of curd in Sicilian purple derived genotype 'PC-1' is controlled by a single incomplete dominant gene. It was supported by the segregation of backcrosses i.e. $\mathrm{B}_{1}\left(\mathrm{~F}_{1} \times \mathrm{DC}-466\right)$ and $\mathrm{B}_{2}\left(\mathrm{~F}_{1} \times \mathrm{PC}-1\right)$, which resulted into prominent classes of curd color such as 24 white: 26 purple (light-medium) $_{\text {and } 0 \text { purple }}$ (dark) and 0 white: 23 purple (light-medium) : 17 purple (dark), respectively.

\section{Segregation of $\mathrm{F}_{2: 3}$ Progenies}

In total, $103 \mathrm{~F}_{2: 3}$ progenies derived from $88 \mathrm{~F}_{2}$ individuals with intermediate curd color, nine with white curding $\mathrm{F}_{2}$ plants, and six with intense purple color were evaluated and the results obtained are presented in Table 2. There was no segregation in white and intense purple color progenies while all of the 88

TABLE 1 | Segregation of $F_{2}$ and backcross population for curd color trait in white: intermediate: purple categories.

\begin{tabular}{|c|c|c|c|c|c|c|c|}
\hline \multirow[t]{2}{*}{ Genotype } & \multirow{2}{*}{$\begin{array}{c}\text { Total } \\
\text { plants }\end{array}$} & \multirow[t]{2}{*}{ White } & \multicolumn{2}{|c|}{ Purple } & \multirow{2}{*}{$\begin{array}{c}\text { Expected } \\
\text { phenotypic } \\
\text { ratio }\end{array}$} & \multirow{2}{*}{$\begin{array}{c}\chi^{2} \\
\text { value }\end{array}$} & \multirow{2}{*}{$\begin{array}{c}P \\
\text { value }\end{array}$} \\
\hline & & & $\begin{array}{l}\text { Light- } \\
\text { medium }\end{array}$ & Intense & & & \\
\hline 'DC-466' & 30 & 30 & 0 & 0 & & & \\
\hline 'PC-1' & 38 & 0 & 0 & 38 & & & \\
\hline$F_{1}$ & 28 & 0 & 28 & 0 & & & \\
\hline $\mathrm{B}_{1}\left(x^{\prime} \mathrm{DC}-466^{\prime}\right)$ & 50 & 24 & 26 & 0 & $1: 1$ & 1.09 & 3.84 \\
\hline $\mathrm{B}_{2}\left(x^{\prime} \mathrm{PC}-1^{\prime}\right)$ & 40 & 0 & 23 & 17 & & & \\
\hline $\mathrm{F}_{2}$ & 173 & 47 & 95 & 31 & $\begin{array}{c}1: 3 \\
(1: 2: 1)\end{array}$ & $\begin{array}{c}0.93 \\
(4.92)\end{array}$ & $\begin{array}{c}3.84 \\
(5.99)\end{array}$ \\
\hline
\end{tabular}

In parentheses, chi-square value for 1:2:1 ratio at $P_{0.05}$ at 2 df. 
TABLE 2 | Segregation of $\mathrm{F}_{2: 3}$ progenies for curd color trait in white:intermediate:purple categories.

\begin{tabular}{|c|c|c|c|c|c|c|c|c|}
\hline \multirow[t]{2}{*}{ Genotype } & \multirow{2}{*}{$\begin{array}{c}\text { No. of } \\
\text { progenies }\end{array}$} & \multirow{2}{*}{$\begin{array}{c}\text { Plants in each } \\
\text { progeny }\end{array}$} & \multirow{2}{*}{$\begin{array}{l}\text { No. of total } \\
\text { plants }\end{array}$} & \multirow[t]{2}{*}{ White } & \multicolumn{2}{|c|}{ Purple } & \multirow{2}{*}{$\begin{array}{c}\text { Expected Phenotypic } \\
\text { ratio }\end{array}$} & \multirow[t]{2}{*}{$\chi^{2}$ value } \\
\hline & & & & & $\begin{array}{l}\text { Light- } \\
\text { medium }\end{array}$ & Intense & & \\
\hline $\mathrm{F}_{2: 3}$ (from Intermediate $\mathrm{F}_{2} \mathrm{~s}$ ) & 88 & $11-18$ & 1,144 & 253 & 604 & 287 & $1: 2: 1$ & $\begin{array}{c}5.60 \\
\left(P_{0.05} \text { at } 2 \mathrm{df}=5.99\right)\end{array}$ \\
\hline $\mathrm{F}_{2: 3}$ (from Intense purple $\mathrm{F}_{2} \mathrm{~s}$ ) & 6 & $12-15$ & 71 & 0 & 0 & 71 & $0: 4$ & \\
\hline $\mathrm{F}_{2: 3}\left(\right.$ from white $\mathrm{F}_{2} \mathrm{~S}$ ) & 9 & $8-13$ & 84 & 84 & 0 & 0 & $4: 0$ & \\
\hline
\end{tabular}

intermediate purple progenies showed segregation for curd color. There were 1,144 plants from 88 progenies which segregated into 253 (white): 604 (light to intermediate purple): 287 (intense purple) fitting well with $1: 2: 1$ ratio $\left(\chi^{2}=5.60 ; P_{2 \mathrm{df}}=5.99\right)$.

\section{Occurrence of 'Broccoli Type' Plants}

We investigated 143 individuals of the $F_{2}$ population from cauliflower cross 'DC-466' $\times$ Sicilian purple 'PC-1' for curd texture which segregated into 30 'PC-1' type, 80 Intermediate type, 33 'DC-466' type (Figures 4A-F). A clear distinction between all three broad types was observed for appearance and size of buds at maturity stage. The bud size and texture of 'PC-1' was observed to be completely different from 'PC-1'. Interestingly, in the 'PC-1' type plants, we also observed six plants having broccoli type heads with medium coarse buds and medium intensity of purple coloration (Figure 4F). There was no segregation in progeny of such an $\mathrm{F}_{2}$ plant 'PC-466-1-76' in $\mathrm{F}_{2: 3}$ generation for head texture and color (Supplementary Figures
1A, B). However, the average size of heads $(310.5 \pm 15.2 \mathrm{~g})$ was smaller than the broccoli $(640.0 \pm 20.4 \mathrm{~g})$. Some plants also formed crude curd with precocious floral bud primordia across its surface prior to floral arrest during head formation.

\section{Apical and Stem Pigmentation Do Not Segregate With Pr Gene}

Further, these $143 \mathrm{~F}_{2}$ plants were observed for apical leaves for purple pigmentation and found that it was present in 42 plants while absent in 101 plants fitting well with the Mendelian ratio of single recessive gene $\left(1: 3\right.$ ratio; $\chi^{2}=0.52 ; \mathrm{P}_{0.5}$ at $\left.1 \mathrm{df}=3.84\right)$ (Figure 5A). Similarly, the stem pigmentation also followed the same trend and plants segregated into 32 (present):111 (absent) plants $\left(1: 3\right.$ ratio; $\chi^{2}=1.47 ; \mathrm{P}_{0.5}$ at $\left.1 \mathrm{df}=3.84\right)$ (Figure 5B). Contrasting pattern for segregation of purple curd phenotype from that of apical and stem pigmentation traits could be due to pigmentation in head portion of 'PC-1' unlike pigmentation in complete curd tissues in 'Graffiti' as shown in Figure 1.

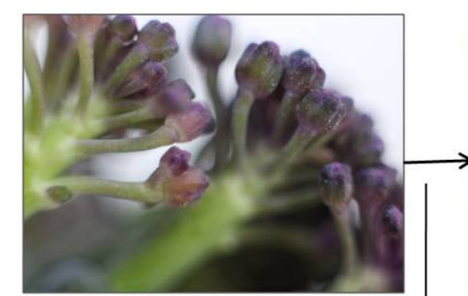

A Broccoli (BoAP1-a BoAP1-a BoCAL-a BoCAL-a)

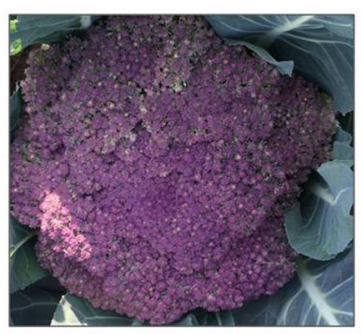

F

Intermediate to Broccoli and PC-1

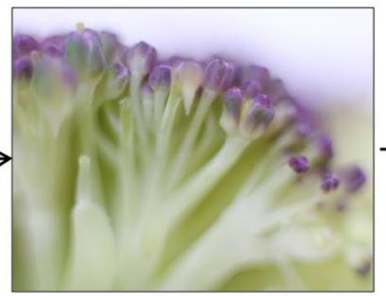

B Sicilian Purple (PC-1) (boapl-a boap1-a BoCAL-a BoCAL-a BoAPI-aBoAPI-a bocal-a bocal-a)

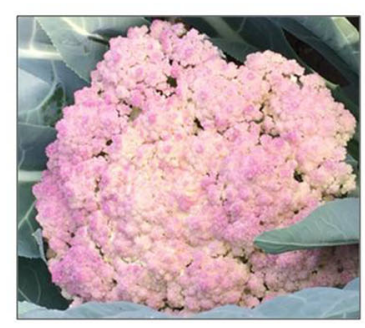

$\mathbf{E}$

Intermediate to PC-1 and DC-466

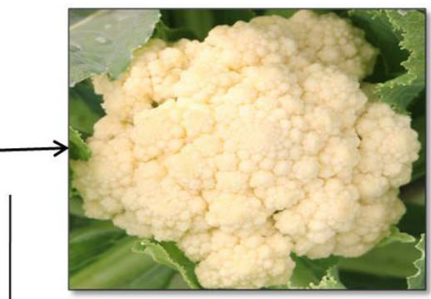

C Cauliflower (DC-466) (boap1-a boap1-a bocal-a bocal-a)

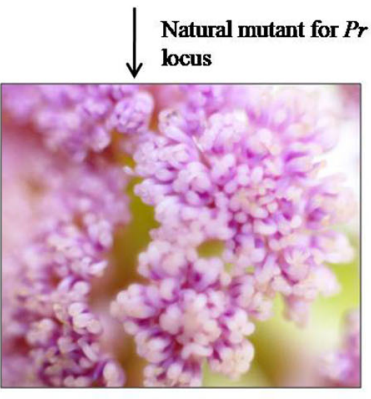

D

Purple Cauliflower (Graffiti)

(boapl-a boapl-a bocal-a bocal-a)* *Proposed genetic composition of curding

FIGURE 4 | Flower buds in knob texture of curd/heads. Broccoli type (A), Sicilian purple 'PC-1' type (B) white cauliflower 'DC-466' (C), purple cauliflower 'Graffiti', (D) intermediate of 'PC-1' and 'DC-466' (E), Intermediate of 'PC-1' and broccoli (F). 

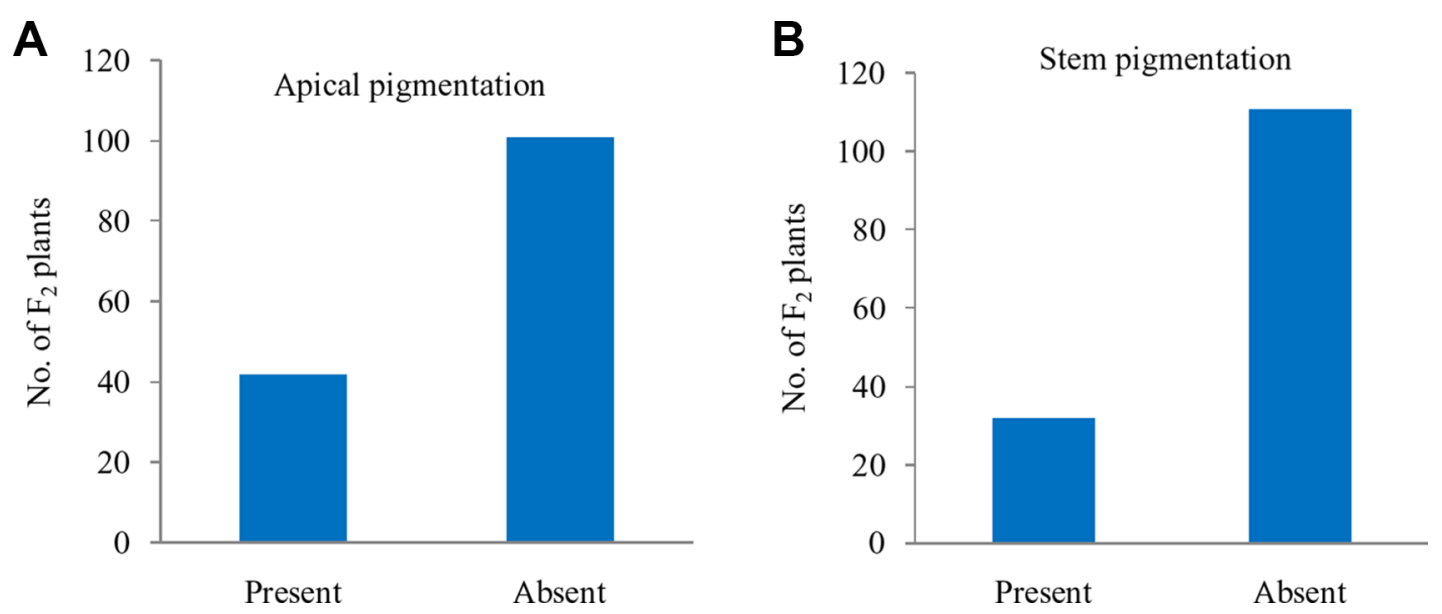

FIGURE 5 | Segregation of $F_{2}$ plants: apical pigmentation (A) and stem pigmentation (B).

\section{Marketable Stage Curds Contain Highest Anthocyanin}

The purple pigmentation in curd fraction of 'PC-1' was increased during curd development and attained most attractive color at full curd stage. However, we attempted a pre-sampling investigation by collecting small fractions of curds at different days i.e. 3, 6, 9, 12, 15, 18, 21, and 24 days after curd initiation in 'PC-1'. The anthocyanin content showed increasing trend from $3^{\text {rd }}$ day $(18.4 \mathrm{mg} / 100 \mathrm{~g} \mathrm{fw})$ to $21^{\text {st }}$ day (41.2 $\mathrm{mg} / 100 \mathrm{~g} \mathrm{fw}$ ) of curd initiation, however, it declined afterward to $34.2 \mathrm{mg} / 100 \mathrm{~g}$ fw on $24^{\text {th }}$ day of curd initiation (Figure 6). This stage was corresponding to the compact and full size harvestable curds.

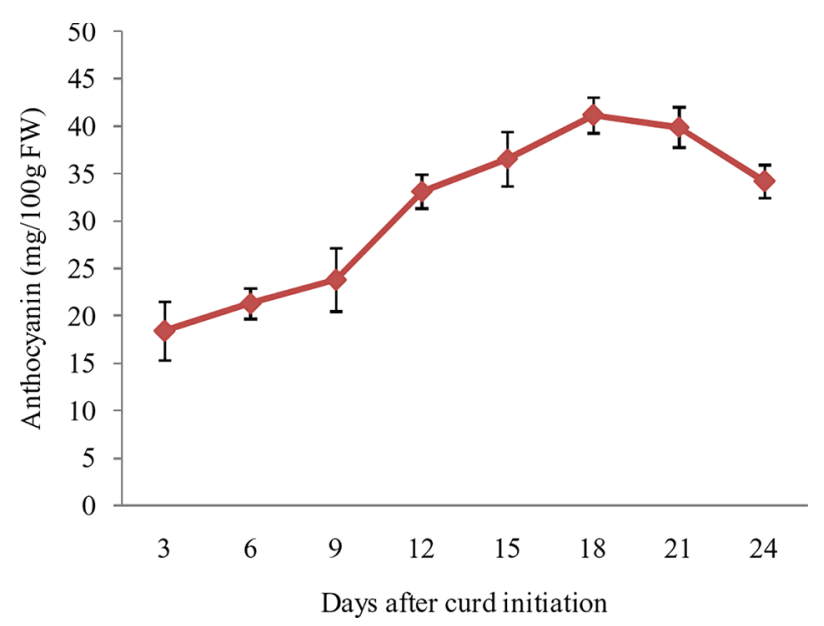

FIGURE 6 | Anthocyanin content in 'PC-1' at different days after curd initiation.

\section{HPLC Analysis of 'PC-1' for Anthocyanin Identification}

The HPLC analysis of curd portion from 'PC-1' for anthocyanins indicated occurrence of only two prominent peaks as cyanidin-3(coumaryl) sophoroside-5-(malonyl) glucoside and cyanidin-3(coumaryl) sophoroside-5-glucoside (Figure 7A). We could observe six peaks for anthocyanins in curd samples of 'Graffiti' but only two of them were prominent (Figure 7B). The only peak for cyanidin 3-(coumaryl) sophoroside-5-(malonyl)glucoside $\left(t_{R}\right.$ : $32.5 \mathrm{~min}$ ) was found to be common in both 'PC-1' and 'Graffiti'.

\section{Anthocyanin Content in $F_{2}$ and $F_{2: 3}$ Populations}

At horticultural maturity, the mean values of anthocyanin content in curds of 'DC-466' was observed to be $<1 \mathrm{mg} / 100 \mathrm{~g}$ $(0.29 \pm 0.33 \mathrm{mg} / 100 \mathrm{~g} \mathrm{FW})$, while intense purple curds of 'PC-1' was found to contain $40.6 \pm 2.74 \mathrm{mg} / 100 \mathrm{~g}$ FW. In $\mathrm{F}_{1}$ plants, it was observed to be $22.40 \pm 4.51 \mathrm{mg} / 100 \mathrm{~g} \mathrm{FW}$ which appears to be intermediate of both the parents. Anthocyanin content ranged from 0.05 to $48.21 \mathrm{mg} / 100 \mathrm{~g} \mathrm{FW}$ in $173 \mathrm{~F}_{2}$ plants with mean value of $18.50 \pm 9.98 \mathrm{mg} / 100 \mathrm{~g} \mathrm{FW}$ (Table 3; Figure 8A). Out of them, 40 plants had $<10 \mathrm{mg} / 100 \mathrm{~g} \mathrm{FW}$, and eight plants were observed to contain anthocyanin $>40 \mathrm{mg} / 100 \mathrm{~g}$ FW. Based on anthocyanin content, we could categorize $\mathrm{F}_{2}$ population into six different groups (at interval of $10 \mathrm{mg} / 100 \mathrm{~g}$ FW) and results are presented in Figure 8B. The distribution of $F_{2}$ plants for anthocyanin content didn't follow the expected normal distribution pattern. Three plants had less than $1.0 \mathrm{mg} / 10 \mathrm{~g}$ FW anthocyanins. Maximum numbers of plants containing anthocyanins were found to be in $11-20 \mathrm{mg} / \mathrm{g}$ FW range (75 plants) followed by $1-10 \mathrm{mg} / \mathrm{g} \mathrm{FW}$ (40 plants) while 38 plants were in $20-30 \mathrm{mg} / 100 \mathrm{~g}$ range, and only eight plants were found to be higher than $40 \mathrm{mg} / 100 \mathrm{~g}$ FW including 'PC-1'.

In $\mathrm{F}_{2: 3}$ progenies, anthocyanin content was $42.50 \pm 1.2 \mathrm{mg} /$ $100 \mathrm{~g} \mathrm{FW}$ in six progenies of $\mathrm{F}_{2}$ (purple) and $0.70 \pm 0.46 \mathrm{mg} / 100$ 


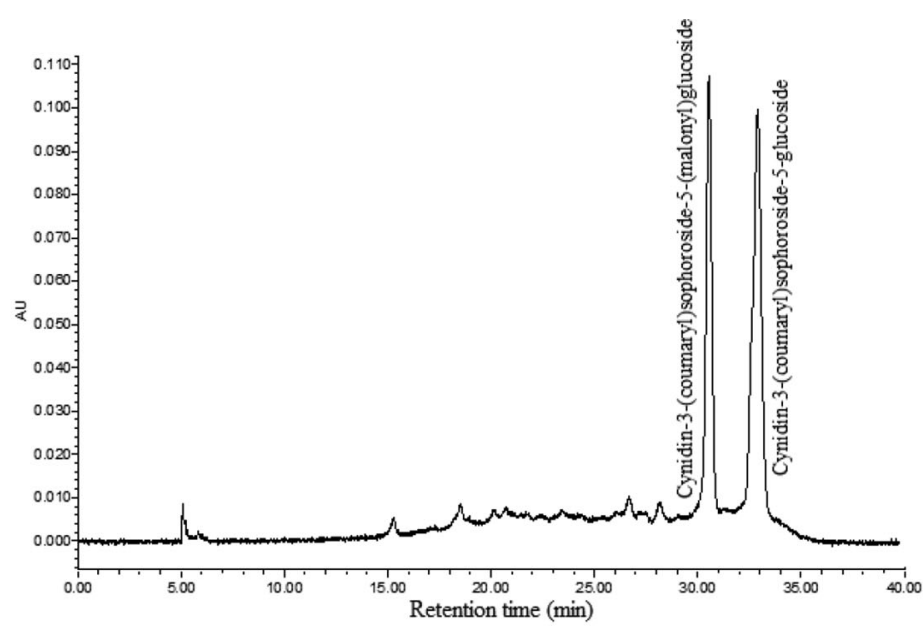

A

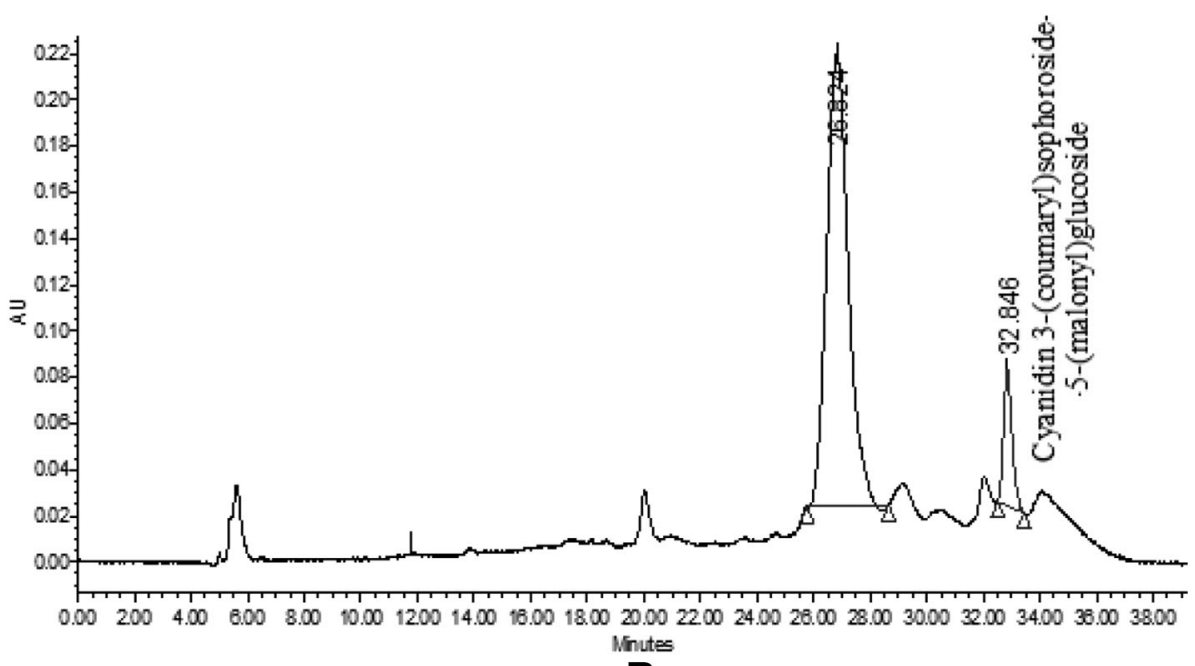

B

FIGURE 7 | HPLC chromatogram of anthocyanin in 'PC-1' (A) and 'Graffiti' (B).

TABLE 3 | Anthocyanin content (mg/100 $\mathrm{g} \mathrm{FW}$ ) in parents, $F_{1}, F_{2}$, and $F_{2: 3}$ of 'DC-466' x 'PC-1' combination.

\begin{tabular}{lccccc}
\hline Genotype & $\begin{array}{c}\text { No. of plants/ } \\
\text { progenies } \\
\text { analyzed }\end{array}$ & Minimum & Maximum & Mean & STDEV \\
\hline 'DC-466' & 3 & 0.10 & 1.13 & 0.298 & 0.325 \\
'PC-1' & 3 & 34.98 & 43.48 & 40.6 & 2.75 \\
$\mathrm{~F}_{1}$ & 2 & 18.23 & 29.58 & 22.4 & 4.51 \\
$\mathrm{~F}_{2}$ & 173 & 0.051 & 48.42 & 18.5 & 9.98 \\
$\mathrm{~F}_{2: 3 \text { (intermediate) }}$ & $88^{*}$ & 2.81 & 50.41 & 19.89 & 10.02 \\
$\mathrm{~F}_{2: 3 \text { (intense purple) }}$ & $6^{*}$ & 40.63 & 44.7 & 42.5 & 1.2 \\
$\mathrm{~F}_{2: 3 \text { (white) }}$ & $9^{*}$ & 0.1 & 2.09 & 0.7 & 0.46 \\
\hline
\end{tabular}

*Bulk samples of progenies. g FW in nine progenies of $\mathrm{F}_{2}$ (white) (Table 3). The $\mathrm{F}_{2}$ population had $2 / 3$ plants with purple (light to intense) curds while anthocyanin content distribution skewed toward the parent 'DC-466' (Figure 8B) suggesting incomplete dominance of mutant phenotype because only 31 plants had the intense purple phenotype. Interestingly, a few $\mathrm{F}_{2}$ plants (8) had anthocyanin content richer that than the 'PC-1' parent, and few (3) also had less anthocyanin than the 'DC-466' parent.

\section{Validation of Molecular Markers}

The already reported nine molecular markers from high resolution map of $\mathrm{Pr}$ gene of purple cauliflower 'Graffiti' were 


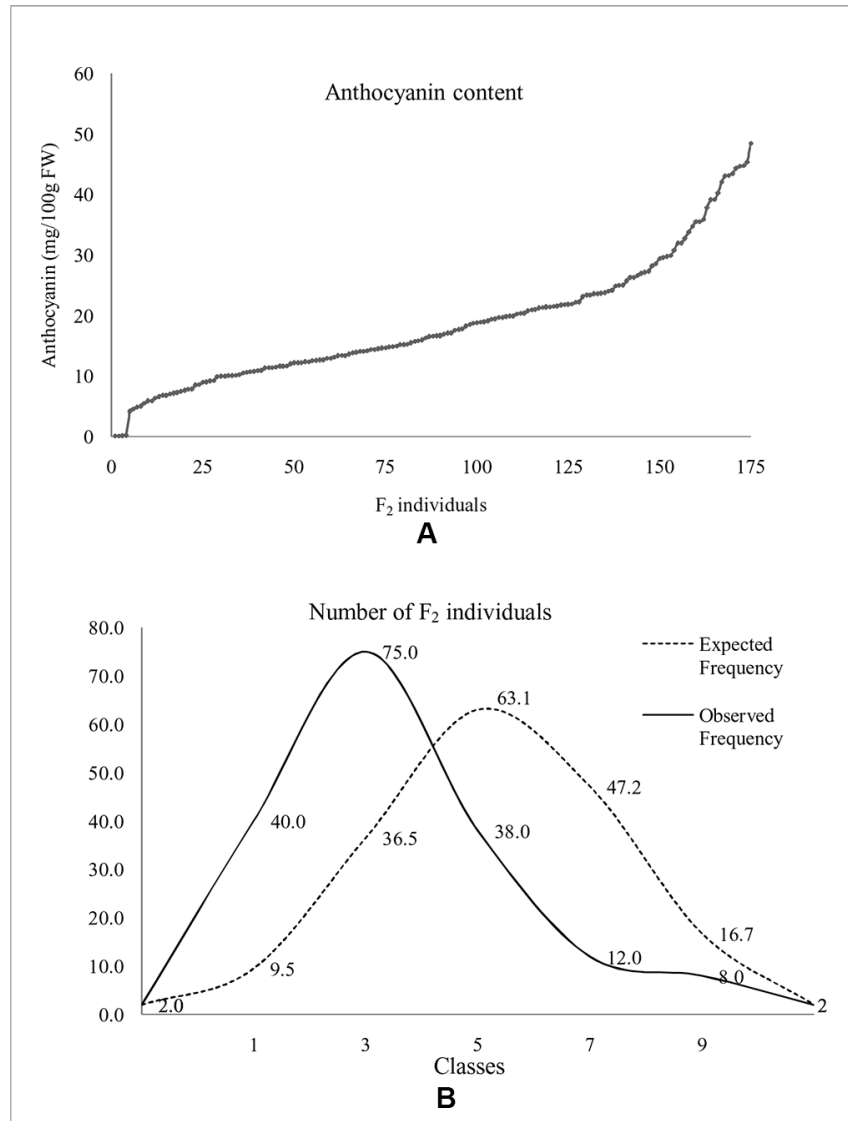

FIGURE 8 | Distribution of anthocyanin content in $F_{2}$ population. Anthocyanin in $F_{2}$ plants $(\mathbf{A})$ and distribution of $F_{2}$ population with reference to normal distribution curve for anthocyanin content based on grouping of 10 $\mathrm{mg} / 100 \mathrm{~g}$ FW series (B). Here, $0=<1 \mathrm{mg}$ or not detectable, $1=1-10 \mathrm{mg}$, $2=11-20 \mathrm{mg}, 3=20-30 \mathrm{mg}, 4=31-40 \mathrm{mg}$, and $5=>40 \mathrm{mg} / 100 \mathrm{~g} \mathrm{FW}$.

first screened in genomic DNA of parents. Except BoMYB2m, all markers were amplified, however, only BoMYB3 could show polymorphism between white and purple curding parents (Table 4). Although, BoMYB2 marker did not produce amplicon in 'Pusa Paushja' (476)' (a white curding genotype) but it failed to distinguish purple and white curding parents (Supplementary Figure 2A). These markers were also tested in five genotypes of white curding Indian cauliflower
[Pusa Shukti (401), DC-402, Pusa Himjyoti (PHJ), Pusa Sharad (309), and Pusa Paushja (476)] and one each of purple broccoli [Pusa purple broccoli (PB)] and green broccoli [Palam Samridhi (PS)]. None of them discriminate between purple cauliflower/ broccoli and white cauliflower/green broccoli (Supplementary Figures 2A-E). The BoMYB3 marker was further used for genotyping of $90 \mathrm{~F}_{2}$ plants, however, it did not show any association with $\operatorname{Pr}$ locus in 'PC-1' (Supplementary Figure 3).

\section{Expression Analysis of Anthocyanin Genes}

The MYB transcription factors play an important role in accumulation of anthocyanins by regulating the transcription of structural genes. Hence, four $M Y B$ genes, namely BoMYB1, $B o M Y B 2, B o M Y B 3$, and BoMYB4 were studied for their expression pattern in parents 'DC-466' and 'PC-1' along with 'Graffiti' as a reference and results are presented in Figures 9A-E. The expression of BoMYB1 gene was up regulated in both the purple curding genotypes 'PC-1' and 'Graffiti' in comparison to 'DC-466'. Although, its expression was approximately 0.20 fold lower in 'Graffiti' as compared to 'PC-1'. The expression of $B o M Y B 2$ gene was however, found to be slightly upregulated in 'PC-1' (by 0.09 fold) and downregulated by 0.83 fold in 'Graffiti'. Both BoMYB3 and BoMYB4 genes were found to be substantially upregulated (29.14 and 9.80 fold, respectively) in 'Graffiti' while the former was down regulated in 'PC-1' by 0.47 fold, the latter, however, showed only 0.83 fold higher expression in 'PC-1' as compared to the white curding genotype 'DC-466'.

\section{DISCUSSION}

'Specialty cauliflowers' or 'rainbow cauliflowers' or 'colorful cauliflowers' taste the same as the normal white varieties, but add splash of colors and nutrients to their food value. In fact, white or 'bleached' cauliflower contains only glucosinolates as a predominant functional constituent of health significance (Verkerk et al., 2009), while purple cauliflower provides anthocyanins additionally (Chiu et al., 2010). The new genotype 'PC-1' developed from exotic collection Sicilian purple produces attractive purple color curds during December to March months as well as flowers and sets seeds satisfactorily in northern plains of India during winter season. The 'PC-1' has

TABLE 4 | Screening of oligonucleotide primers in parents, bulk, and reference lines.

\begin{tabular}{|c|c|c|c|c|c|c|c|c|c|c|c|c|}
\hline Primer & $\begin{array}{c}\text { No. of } \\
\text { amplico- } \\
n\end{array}$ & $\begin{array}{c}\text { Amplico- } \\
\text { n size } \\
\text { (bp) }\end{array}$ & 'DC-466' & 'PC-1' & $\begin{array}{c}\text { Bulk } \\
\text { (white) }\end{array}$ & $\begin{array}{c}\text { Bulk } \\
\text { (purple) }\end{array}$ & $\begin{array}{c}\text { Green } \\
\text { broccoli }\end{array}$ & $\begin{array}{c}\text { Purple } \\
\text { broccoli }\end{array}$ & 309 & PHJ & 476 & $\begin{array}{l}\text { Polymorphism } \\
\text { for purple curd }\end{array}$ \\
\hline BoMYB1 & One & 130 & + & + & + & + & + & + & + & + & + & Monomorphic \\
\hline BoMYB2 & One & 331 & + & + & + & + & + & + & + & + & - & Monomorphic \\
\hline BoMYB3 & One & 110 & - & + & - & + & - & - & - & - & - & Polymorphic \\
\hline BoMYB4 & One & 264 & + & + & + & + & + & + & + & + & - & Monomorphic \\
\hline BoMYB2m & One & 190 & + & + & + & + & + & + & + & + & + & Monomorphic \\
\hline BoMYB2m & - & - & - & - & - & - & - & - & - & - & - & No amplification \\
\hline BoMYB3m & One & 400 & - & + & - & + & - & - & - & - & + & Monomorphic \\
\hline BoMYB4m & One & 110 & + & + & + & + & + & + & + & + & + & Monomorphic \\
\hline BoMYB4mR & One & 130 & + & + & + & + & + & + & + & + & + & Monomorphic \\
\hline
\end{tabular}

Amplicon present (+), absent (-). 


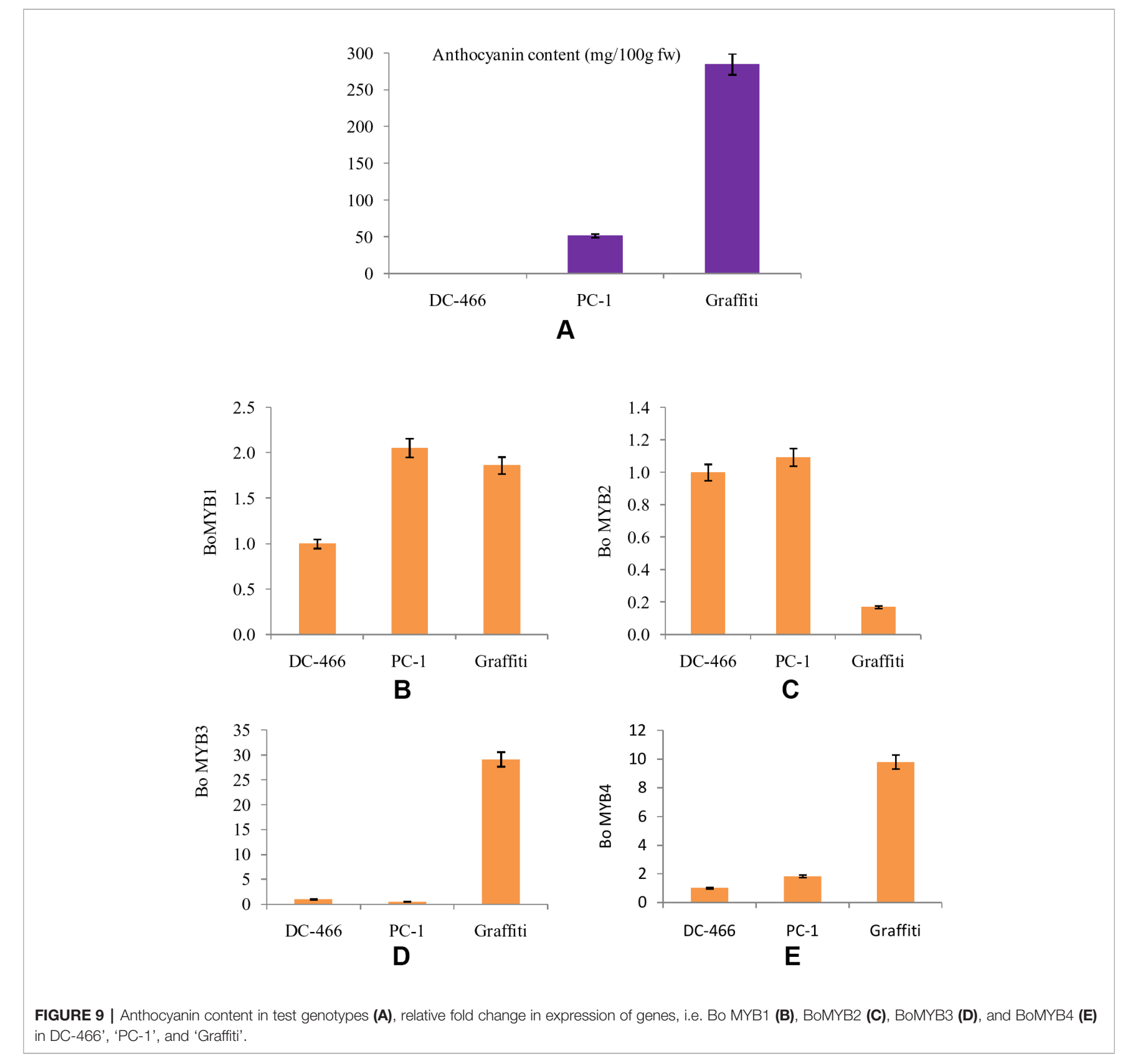

purple pigmentation on apical and stem regions but intensity is low as compared to the 'Graffiti'.

The segregation of $\mathrm{F}_{2}$ population was from white to intense purple, but it had a range from slight to intense pigmentation. Hence, we made three major classes i.e. white, light to medium purple, and intense purple curds for ease of interpretation of data. The observed values for segregation of $F_{2}$ plants are in agreement with 1:3 for white: purple curds but they were following 1:2:1 ratio for white: intermediate: intense purple color similar to 'Graffiti' purple cauliflower reported by Chiu et al. (2010). Further, the segregation $F_{2: 3}$ progenies for curd color supported single semi-dominant gene for purple color curd trait. This indicates that the purple pigmentation in curd portion of cauliflower and head portion of Sicilian purple has similar genetic control despite variation in pigmented portion which is pre-floral apical meristem and pre-mature flower buds, respectively. However, the observations for purple pigmentation on apical shoot and stem parts in $143 \mathrm{~F}_{2}$ plants indicated for their recessive nature and single locus governance.

Occurrence of broccoli type plants in segregating $\mathrm{F}_{2}$ population could be due to influence of modifier genes on the degree and stage of inflorescence arrest and modification from the Indian cauliflower genotype 'DC-466'. Unlike cauliflower curds which represents proliferation of arrested inflorescence and floral meristem (Carr and Irish, 1997), these plants produced broccoli-like heads with inflorescence spikes developed as a loose 
collection of immature flower buds. Distinct variation between buds of mature stage heads and curds in all three types could occur due to genetic factors. Although, occurrence of such plants is difficult to explain purely by 'two gene theory' of Smith and King (2000) for broccoli (Calabrese) to Sicilian purple to cauliflower domestication process, hence we believed that certain modifier genes for flowering trait (because broccoli heads are made up of immature flower buds) are playing a role in this phenomenon. The role of such genes in heading traits in Brassicas has already been suggested by Smith and King (2000). These modifier genes in Indian cauliflower might have evolved during its evolutionary process from European materials during past 200 years (i.e. after introduction from Europe in 1822) as a part of adaptive mechanism in cauliflower for sub-tropical Indian conditions. According to them, the Sicilian purple is an intermediate (boap1-a boap1-a BoCAL-a BoCAL-a or BoAP1aBoAP1-a bocal-a bocal-a) type of Calabrese broccoli (BoAP1aBoAP1- $a$ BoCAL-a BoCAL-a) and cauliflower (boap1-a boap1-a bocal-a bocal-a). We purified the Sicilian purple exotic materials and fixed genotype 'PC-1' supposed to have boap1-a boap1-a BoCAL-a BoCAL-a or BoAP1-aBoAP1-a bocal-a bocal-a genes and with these gene combinations, it is difficult to get typical broccoli type plants (which should have BoAP1-a BoAP1-a $B o C A L-a$ BoCAL- $a$ in $\mathrm{F}_{2}$ but occurrence of heterozygous state of one of the two genes in 'PC-1' along with unknown tropical flowering genes and associated modifiers in Indian cauliflower might be leading to delay in inflorescence restriction stage from pre-floral apical meristem in curd (as in cauliflower) to immature floral buds (as in broccoli type plants). Hence, we propose the role of some other gene(s) in Indian cauliflower which led to occurrence of broccoli type plants in segregating materials from 'DC-466' $\times$ 'PC-1' combination, however it needs further investigation.

By HPLC analysis, we observed two prominent peaks for anthocyanins in curd samples of 'PC-1' and 'Graffiti'. However, 'Graffiti' also had four additional peaks as reported earlier by Chiu et al. (2010) including cyanidin 3-(coumaryl-caffeyl) glucoside-5- (malonyl)glucoside as prominent peak along with minor peaks for cyanidin 3-sophoroside-5-glucoside $\left(t_{R}: 4.0\right.$ $\min )$, cyanidin 3-sophoroside-5-(malonyl)glucoside $\left(t_{R}: 8.2\right.$ min), cyanidin 3-(coumaryl)sophoroside-5-(malonyl)glucoside $\left(t_{R}: 32.5 \mathrm{~min}\right)$, cyanidin 3-(coumaryl)sophoroside-5-glucoside $\left(t_{R}: 43.6 \mathrm{~min}\right)$, and cyanidin 3-(ferulyl-caffeyl)sophoroside-5(malonyl)glucoside $\left(t_{R}: 60.5 \mathrm{~min}\right.$ ) by use of HPLC electrospray ionization (ESI)-tandem mass spectrometry. Only cyanidin 3(coumaryl) sophoroside-5-(malonyl) glucoside appears to be common in both the purple genotypes. The variations in number or peaks and anthocyanin content could be due to change in genotypes, expression of gene(s) depending upon sites of anthocyanin accumulation and laboratory instruments. In 'PC-1', anthocyanin is present only in pre-floral buds while in 'Graffiti', it expresses in pre-floral meristem and stalk portions.

In present study, the anthocyanin content were found to be less

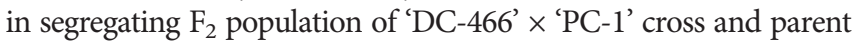
genotype 'PC-1' in contrast to earlier reports of Chiu et al. (2010) in purple cauliflower variety 'Graffiti' (315 mg/100 g fw). This was mainly due to the genotype effect and also due to anthocyanin pigmentation site which appeared to be only pre-floral buds in 'PC1 ' and pre-floral meristematic tissues in curd portion of 'Graffiti'. However, high level of anthocyanin content in five $\mathrm{F}_{2}$ plants than the 'PC-1' indicated transgressive segregation for anthocyanin content due to modifier genes which might be involved in regulating anthocyanin biosynthesis or accumulation.

Scalzo et al. (2008) reported total anthocyanin content of 75.6 $\mathrm{mg} / 100 \mathrm{~g} \mathrm{fw}$ in red cabbage and $4.21 \mathrm{mg} / 100 \mathrm{~g}$ in violet cauliflower in addition to differences in pigment compositions of both the crops. Besides, anthocyanin in 'PC-1' was also less than that of red cabbage ( 50 to $182 \mathrm{mg} / 100 \mathrm{~g} \mathrm{fw}$ ) as reported by Yuan et al. (2009), which was mainly due to difference in pigmented tissues. Interestingly, anthocyanins from cabbage have strong antioxidant activity $(22.0 \mathrm{mmol} \mathrm{Fe}(\mathrm{II}) / \mathrm{g} \mathrm{fw})$, which is approximately 10-fold higher than green cabbage (Yuan et al., 2009), suggesting for similar studies with purple cauliflower. Further, Jana et al. (2017) reported total anthocyanin content in red cabbage extract was found to be $86.004 \pm 3.103 \mathrm{mg} / 100 \mathrm{~g}$ and elucidated the mechanism of ARCE mediated prevention of experimentally induced myocardial damage in rodent model. These investigations suggests for further studies to understand the potential of purple color Brassica vegetables for good health.

The molecular markers are useful tools for early stage detection of purple curding plants, otherwise we have to wait for curding stage to identify desirable plants in breeding materials. Notably, pigmentation in 'PC-1' gradually increases with curd maturity and reaches its peak at harvest maturity. Because of this, the curds of 18 to 21 days stage observed to have highest anthocyanin content, and it appears to follow sigmoidal kinetics in various plants as showed by Rogez et al. (2011) in acai fruits (Euterpe oleracea). To avoid this waiting period, the molecular markers (BoMYB2, BoMYB3, and BoMYB4), from a previously reported high resolution map for $\operatorname{Pr}$ gene in 'Graffiti' (Chiu et al., 2010), were used but they could not reproduce similar results in 'PC-1'. However, BoMYB3 showed polymorphism between white and purple curding parents, but their segregation with purple curd didn't show close association. Hence, we recommend for analysis of more number of markers to find linked markers. The polymorphism between two could be due to diverse nature of genetic constitution, because Sicilian purple and Indian cauliflower evolved in two different eco-geographical regions. BoMYB2 and BoMYB4 markers could not differentiate the white and purple curding parental genotypes as well. Further, these markers could not distinguish purple broccoli/Sicilian purple from white curding genotypes. Hence, it appears that (i) these markers are specific to purple cauliflower 'Graffiti' and (ii) source gene(s) for purple color in Sicilian purple is different from 'Graffiti'. This was due to difference in genotypes because Chiu et al. (2010) used 'Graffiti' as source of ' $P r$ ' gene while we used 'Sicilian purple' and the both genotypes had differences in evolution, kind of major anthocyanins, and site of accumulation and also showed variation in content of anthocyanin. The 'Graffiti' was evolved as a natural mutant (Chiu et al., 2010) while Sicilian purple was evolved as an intermediate of Calabrese and cauliflower during its evolution process (Smith and King, 2000). 
Further, anthocyanin biosynthesis in plants is regulated by transcriptional regulation of structural genes. MYB transcription factors constitute one of the major families of anthocyanin regulatory proteins which activate expression of anthocyanin structural genes as reviews in maize by Sainz et al. (1994). Regulatory genes were reported in different crops like anthocyanin2 in Petunia flowers (Quattrocchio et al., 1999), IbMYB1 gene in sweet potato tubers (Mano et al., 2007), $B o M Y B 2$ in pre-floral apical meristematic region of purple cauliflower 'Graffiti' (Chiu and Li, 2012), and RsUFGT gene in radish roots (Muleke et al., 2017). During the present investigations, the expression of four BoMYB (BoMYB1, $B o M Y B 2, B o M Y B 3$, and $B o M Y B 4)$ genes was studied, and we observed that expression of $B O M Y B 1$ and $B O M Y B 2$ was higher in 'PC-1' than the white curded 'DC-466' and bright purple curded variety 'Graffiti'. BoMYB3 and BoMYB4 genes were found to be expressed at a very high level in Graffiti, however, BoMYB3 was down regulated in PC-1 while the expression of BoMYB4 was a bit higher in 'PC-1' compared to 'DC-466', but was substantially lower than 'Graffiti'. These observations indicate that different modes of regulations of anthocyanin pathway are operational in 'PC-1' and 'Graffiti'. Both the genotypes differ for their evolutionary process, kind, and concentration of anthocyanin and also for site of accumulation. In red cabbage, increased expression of BoMYB2 was and reduced expression of BoMYB3 was associated with enhanced anthocyanin production (Yuan et al., 2009) which appears to be partially true for 'PC-1'.

\section{CONCLUSION}

The 'purple cauliflower-1' (or PC-1) genotype, developed through recurrent selection, was found to be a promising colored cauliflower rich in anthocyanin. The study revealed that genetics of purple curds in Sicilian purple 'PC-1' appears to be governed by single semi-dominant gene similar to purple cauliflower 'Graffiti'. However, the position of the Pr locus appears to be quite different as none of the markers from high resolution map of Pr locus reported earlier by Chiu et al. (2010) could produce similar results. It was revealed by monomorphic banding pattern in purple 'PC-1' and white 'DC-466' and variation in gene expression pattern in 'PC-1' and 'Graffiti'. Hence, identification of markers is essential for early seeding stage detection of desirable plants in breeding materials, because

\section{REFERENCES}

Barker, D. H., Seaton, G. G. R., and Robinson, S. A. (1996). Internal and external photoprotection in developing leaves of the CAM plant Cotyledon orbiculata. Plant Cell Environ. 20, 617-620. doi: 10.1111/j.1365-3040.1997.00078.x

Birol, E., Meenakshi, J. V., Oparinde, A., Perez, S., and Tomlins, K. (2015). Developing country consumers' acceptance of biofortified foods: a synthesis. Food Secur. 7 (3), 555-668. doi: 10.1007/s12571-015-0464-7

Branca, F., Chiarenza, G. L., Cavallaro, C., Gu, H., Zhao, Z., and Tribulato, A. (2018). Diversity of Sicilian broccoli (Brassica oleracea var. italica) and cauliflower (Brassica oleracea var. botrytis) landraces and their distinctive bio-morphological, antioxidant, and genetic traits. Genet. Resour. Crop Evol. 65, 485-502. doi: 10.1007/s10722-017-0547-8 the purple pigmentation on apical shoot and stem parts did not segregate with curd color. Interestingly, occurrence of broccoli type plants in $\mathrm{F}_{2}$ generation and non-segregation of $\mathrm{F}_{2: 3}$ progeny of one such plant warrants for further studies.

\section{DATA AVAILABILITY STATEMENT}

All datasets for this study are included in the article/ Supplementary Material.

\section{AUTHOR CONTRIBUTIONS}

SSi and PK conceived the concept. SSi developed and evaluated breeding material, analyzed data, and drafted manuscript. PK introduced 'Sicilian purple' and initiated recurrent selection for development of 'PC-1'. RM supported phenotypic observation, performed anthocyanin determination and marker analysis. MM did qPCR expression analysis and drafted the relevant part. SI helped in anthocyanin determination. SSa carried out HPLC analysis. BT supported overall field experimentation. SSi, PK and MM read the manuscript and approved.

\section{FUNDING}

The research was carried out in an in-house project and for that the funding for the research was received from ICAR-Indian Agricultural Research Institute, New Delhi.

\section{ACKNOWLEDGMENTS}

Authors are thankful to Director, ICAR-Indian Agricultural Research Institute, New Delhi for financial support and experimentation facilities for conducting the research.

\section{SUPPLEMENTARY MATERIAL}

The Supplementary Material for this article can be found online at: https://www.frontiersin.org/articles/10.3389/fpls.2019. 01766/full\#supplementary-material

Broun, P. (2005). Transcriptional control of flavonoid biosynthesis: a complex network of conserved regulators involved in multiple aspects of differentiation in Arabidopsis. Curr. Opin. Plant Biol. 8, 272-279. doi: 10.1016/j.pbi.2005.03.006

Carr, S. M., and Irish, V. F. (1997). Floral homeotic gene expression defines developmental arrest stages in Brassica oleracea L. vars. botrytis and italica. Planta 201 (2), 179-188. doi: 10.1007/BF01007702

Chinese Nutrition Society (2013). Chinese DRIs Handbook (Beijing (China): Standards Press of China).

Chiu, L., and Li, L. (2012). Characterization of the regulatory network of BoMYB2 in controlling anthocyanin biosynthesis in purple cauliflower. Planta 236, 1153-1164. doi: 10.1007/s00425-012-1665-3

Chiu, L., Prior, R. L., Wu, X., and Li, L. (2005). "Toward identification of the candidate gene controlling anthocyanin accumulation in purple cauliflower 
(Brassica oleracea L. var. botrytis)," (Seattle, USA: American Society of Plant Biologists Annual Meeting), 628.

Chiu, L. W., Zhou, X., Burke, S., Wu, X., Prior, R. L., and Li, L. (2010). The purple cauliflower arises from activation of a MYB transcription factor. Plant Physiol. 154 (3), 1470-1480. doi: 10.1104/pp.110.164160

Christian, K. R., Nair, M. G., and Jackson, J. C. (2006). Antioxidant and cyclooxygenase inhibitory activity of sorrel (Hibiscus sabdariffa). J. Food Compos. Anal. 19, 778-783. doi: 10.1016/j.jfca.2006.04.004

Dodd, I. C., Critchley, C., Woodall, G. S., and Stewart, G. R. (1998). Photoinhibition in different colored juvenile leaves of Syzgium species. J. Exp. Bot. 49, 1437-1445. doi: 10.1093/jxb/49.325.1437

FAOSTAT (2017). Food and Agriculture Organization, Rome. Download on 22 July 2019.

Fulecki, T., and Francis, F. J. (1968). Quantitative methods for anthocyanins. 1. Extraction and determination of total anthocyanin in cranberries. J. Food Sci. 33, 72-77. doi: 10.1111/j.1365-2621.1968.tb00887.x

Gonzalez, A., Zhao, M., Leavitt, J. M., and Lloyd, A. M. (2008). Regulation of the anthocyanin biosynthetic pathway by the TTG1/bHLH/Myb transcriptional complex in Arabidopsis seedlings. Plant J. 53 (5), 814-827. doi: 10.1111/j.1365313X.2007.03373.x

Gray, A. R. (1982). Taxonomy and evolution of broccoli (Brassica oleracea var. italica). Econ. Bot. 36, 397-410. doi: 10.1007/BF02862698

Grotewold, E., Sainz, M. B., Tagliani, L., Hernandez, J. M., Bowen, B., and Chandler, V. L. (2000). Identification of the residues in the Myb domain of maize C1 that specify the interaction with the bHLH cofactor R. Proc. Natl. Acad. Sci. U.S.A. 97, 13579-13584. doi: 10.1073/pnas.250379897

Hou, D. X., Ose, T., Lin, S., Harazoro, K., Imamura, I., Kubo, M., et al. (2003). Anthocyanidins induce apoptosis in human promyelocytic leukemia cells: structure-activity relationship and mechanisms involved. Int. J. Oncol. 23 (3), 705-712. doi: 10.3892/ijo.23.3.705

Hou, D. X., Fujii, M., Terahara, N., and Yoshimoto, M. (2004a). Molecular mechanisms behind the chemopreventive effects of anthocyanidins. $J$. Biomed. Biotechnol. 2004 (5), 321-325. doi: 10.1155/S1110724304403040

Hou, D. X., Kai, K., Li, J. J., Lin, S., Terahara, N., Wakamatsu, M., et al. (2004b). Anthocyanidins inhibit activator protein 1 activity and cell transformation: structure-activity relationship and molecular mechanisms. Carcinogenesis 25 (1), 29-36. doi: 10.1093/carcin/bgg184

Hwang, J. W., Kim, E. K., Lee, S. J., Kim, Y. S., Choi, D. K., Park, T. K., et al. (2012). Anthocyanin effectively scavenges free radicals and protects retinal cells from $\mathrm{H}_{2} \mathrm{O}_{2}$-triggered G2/M arrest. Eur. Food Res. Technol. 234 (3), 431-439. doi: 10.1007/s00217-011-1648-9

Jana, S., Patel, D., Patel, S., Upadhyay, K., Thadani, J., Mandal, R., et al. (2017). Anthocyanin rich extract of Brassica oleracea L. alleviates experimentally induced myocardial infarction. PLoS ONE 12 (8), e0182137. doi: 10.1371/journal.pone.0182137

Kalia, P., Singh, S., Prakash, C., and Dey, S. S. (2016). Cole vegetables enhancing volume of vegetable basket. Indian Hort. 61 (6), 77-81.

Klaper, R., Frankel, S., and Berenbaum, M. R. (1996). Anthocyanin content and UVB sensitivity in Brassica rapa. Photochem. Photobiol. 63, 811-813. doi: 10.1111/j.1751-1097.1996.tb09635.x

Kong, J. M., Chia, L. S., Goh, N. K., Chia, T. F., and Brouillard, R. (2003). Analysis and biological activities of anthocyanins. Phytochemistry 64, 923-933 doi: doi:10.1016/S0031-9422(03)00438-2.

Lila, M. A. (2004). Anthocyanins and human health: an in vitro investigative approach. J. Biomed. Biotechnol. 2004 (5), 306-313. doi: 10.1155/S111072430440401X

Liu, X. P., Gao, B. Z., Han, F. Q., Yang, L. M., Zhuang, M., Lv, H. L., et al. (2017). Genetics and fine mapping of a purple leaf gene, $\mathrm{BoPr}$, in ornamental kale (Brassica oleracea L. var. acephala). BMC Genomics 18, 230. doi: 10.1186/s12864-017-3613-X

Mano, H., Ogasawara, F., Sato, K., Higo, H., and Minobe, Y. (2007). Isolation of a regulatory gene of anthocyanin biosynthesis in tuberous roots of purple-fleshed sweet potato. Plant Physiol. 143 (3), 1252-1268. doi: 10.1104/pp.106.094425

Muleke, E., Fan, L., Wang, Y., Xu, L., Zhu, X., Zhang, W., et al. (2017). Coordinated regulation of anthocyanin biosynthesis genes confers varied phenotypic and spatial-temporal anthocyanin accumulation in radish (Raphanus sativus L.). Front. Plant Sci. 8, 1243. doi: 10.3389/fpls.2017.01243

N. H. B. Database (2017). National Horticulture Database (Gurugram, India: National Horticulture Board). http://nhb.gov.in.

Nesi, N., Debeaujon, I., Jond, C., Pelletier, G., Caboche, M., and Lepiniec, L. (2000). The TT8 gene encodes a basic helix-loop-helix domain protein required for expression of DFR and BAN genes in Arabidopsis siliques. Plant Cell 12, 1863-1878. doi: 10.1105/tpc.12.10.1863

Ozcan, A., and Ogun, M. (2015). "Biochemistry of reactive oxygen and nitrogen species," in Basic Principles and Clinical Significance of Oxidative Stress. Eds S. J. T. (London, U. K.: IntechOpen). doi: 10.5772/61193

Quattrocchio, F., Wing, J., van der Woude, K., Souer, E., de Vetten, N., Mol, J., et al. (1999). Molecular analysis of the anthocyanin2 gene of petunia and its role in the evolution of flower color. Plant Cell 11 (8), 1433-1444. doi: 10.1105/tpc.11.8.1433

Quiros, C. F., and Farnham, M. W. (2011). "The Genetics of Brassica oleracea," in Genetics and Genomics of the Brassicaceae. Eds. R. Schmidt and I. Bancroft (New York: Springer), 261-289. doi: 10.1007/978-1-4419-7118-0

Ren, J., Liu, Z. Y., Niu, R. Q., and Feng, H. (2015). Mapping of Re, a gene conferring the red leaf trait in ornamental kale (Brassica oleracea. L. var. acephala). Plant Breed. 134, 494-500. doi: 10.1111/pbr.12286

Rogez, H., Pompeu, D. R., Akwie, S. N. T., and Larondelle, Y. (2011). Sigmoidal kinetics of anthocyanin accumulation during fruit ripening: a comparison between acai fruits (Euterpe oleracea) and other anthocyanin-rich fruits. $J$. Food Comp. Anal. 24 (6), 796-800. doi: 10.1016/j.jfca.2011.03.015

Saghai-Maroof, M. A., Soliman, K. M., Jorgensen, R. A., and Allard, R. W. L. (1984). Ribosomal DNA spacer-length polymorphisms in barley: Mendelian inheritance, chromosomal location, and population dynamics. Proc. Natl. Acad. Sci. U.S.A. 81 (24), 8014-8018. doi: 10.1073/pnas.81.24.8014

Sainz, M. B., Goff, S. A., Krahn, J. M., and Chandler, V. L. (1994). "Transcriptional Regulation of the Maize Anthocyanin Pathway," in Plant Molecular Biology. Eds. G. Coruzzi and P. Puigdomenech (Berlin, Heidelberg: NATO ASI Series H: Cell Biology, Springer), 81.

Scalzo, R. L., Genna, A., Branca, F., Chedin, M., and Chassaigne, H. (2008). Anthocyanin composition of cauliflower (Brassica oleracea L. var. botrytis) and cabbage (B. oleracea L. var. capitata) and its stability in relation to thermal treatments. Food Chem. 107 (1), 136-144. doi: 10.1016/j.foodchem.2007.07.072

Singh, R., and Sharma, S. R. (2003). "Cauliflower," in Textbook on Vegetables, Tubercrops and Spices. Eds. S. Thamburaj and N. Singh (New Delhi: Indian Council of Agricultural Research), 76-97.

Singh, S., Kalia, P., Tomar, B. S., and Meena, R. K. (2019).Breeding antioxidant rich 'Speciality cauliflowers': a plant way to tackle human health, in: XIV Agricultural Science Congress (Abstracts), NASC, Pusa, New Delhi, India, 2023 February, 2019. p. 573.

Smith, L. B., and King, G. (2000). The distribution of BoCAL-a alleles in Brassica oleracea is consistent with a genetic model for curd development and domestication of the cauliflower. Mol. Breed. 6 (6), 603-613. doi: 10.1023/A:1011370525688

Verkerk, R., Schreiner, M., Krumbein, A., Ciska, E., Holst, B., Rowland, I., et al. (2009). Glucosiolates in Brassica vegetables: The influence of the food supply chain on intake, bioavailability and human health. Mol. Nutr. Food Res. 53, S219-S265. doi: 10.1002/mnfr.200800065

Wallace, T. C., and Giusti, M. M. (2015). Anthocyanins. Adv. Nutr. 6, 620-622. doi: 10.3945/an.115.009233

Wang, W., Zhang, D., Yu, S., Liu, J., Wang, D., Zhang, F., et al. (2014). Mapping the BrPur gene for purple leaf color on linkage group A03 of Brassica rapa. Euphytica 199 (3), 293-302. doi: 10.1007/s10681-014-1128-y

Welch, C. R., Wu, Q., and Simon, J. E. (2008). Recent advances in anthocyanin analysis and characterization. Curr. Anal. Chem. 4 (2), 75-101. doi: 10.2174/157341108784587795

$\mathrm{Wu}, \mathrm{X}$., and Prior, R. L. (2005). Systematic identification and characterization of anthocyanins by HPLC-ESI-MS/MS in common foods in the United States: fruits and berries. J. Agric. Food Chem. 53 (7), 2589-2599. doi: 10.1021/jf048068b

Yuan, Y., Chiu, L. W., and Li, L. (2009). Transcriptional regulation of anthocyanin biosynthesis in red cabbage. Planta 230, 1141-1153. doi: 10.1007/s00425-009-1013-4

Conflict of Interest: The authors declare that the research was conducted in the absence of any commercial or financial relationships that could be construed as a potential conflict of interest.

Copyright (c) 2020 Singh, Kalia, Meena, Mangal, Islam, Saha and Tomar. This is an open-access article distributed under the terms of the Creative Commons Attribution License (CC BY). The use, distribution or reproduction in other forums is permitted, provided the original author(s) and the copyright owner(s) are credited and that the original publication in this journal is cited, in accordance with accepted academic practice. No use, distribution or reproduction is permitted which does not comply with these terms. 